\title{
Responses of the skin microcirculation to acetylcholine and sodium nitroprusside in patients with NIDDM
}

\author{
S. J. Morris, A. C. Shore, J. E. Tooke \\ Department of Diabetes and Vascular Medicine, Postgraduate Medical School, University of Exeter, Exeter, UK
}

Summary The mechanisms involved in the pathogenesis of microangiopathy occurring in non-insulin-dependent diabetes mellitus (NIDDM) are unclear. In the present study, blood flow responses to the vasodilators acetylcholine (which acts via the endothelium) and sodium nitroprusside (a smooth muscle relaxant) were evaluated in this patient group. In 14 male patients with NIDDM, treated with either diet alone $(n=6)$ or diet plus insulin, (mean age 59 years) and 14 age-pair-matched control subjects, forearm skin perfusion following multiple doses of iontophoretically applied $1 \%$ acetylcholine and $0.01 \%$ sodium nitroprusside was recorded by laser Doppler perfusion imaging. Basal skin blood flow was not significantly different in the diabetic group compared with the control group. The following results are expressed as drug-minus-vehicle response. Acetylcholine significantly increased forearm skin perfusion $(p<0.001$, analysis of variance) in all subjects, but the vasodilatation was attenuated in the patient group compared with control subjects $(0.86 \pm 0.09$ vs $1.36 \pm 0.14$ arbitrary units of volts (V) respectively, at the fifth measurement point, mean $\pm \mathrm{SEM}, p<0.01$ ). Skin perfusion significantly increased following sodium nitroprusside $(p<0.001)$ but was lower in patients than control subjects $(0.12 \pm 0.05$ vs $0.45 \pm 0.11 \mathrm{~V}$, respectively, at the fifth measurement point, $p<0.01$ ). These data suggest that endothelial and/or smooth muscle function may be impaired in the skin microcirculation of patients with NIDDM. [Diabetologia (1995) 38: 1337-1344]

Key words Endothelium, microcirculation, non-insulin-dependent diabetes mellitus, skin, vascular smooth muscle.
It has been proposed that haemodynamic factors are involved in the pathogenesis of diabetic microangiopathy [1]. In support of this hypothesis both capillary pressure [2] and capillary filtration coefficient [3] are increased in patients with insulin-dependent diabetes mellitus (IDDM) particularly in those at risk of diabetic nephropathy. The prevalence of microvascular

Received: 2 February 1995 and in revised form: 12 May 1995

Corresponding author: Ms. S. J. Morris, Department of Diabetes and Vascular Medicine, Postgraduate Medical School, Barrack Road, Exeter EX2 5AX, UK

Abbreviations: IDDM, Insulin-dependent diabetes mellitus; LDPI, laser Doppler perfusion imager; $\mathrm{mA}$, milliamp; $\mathrm{mC}$, millicoulomb; NIDDM, non-insulin-dependent diabetes mellitus; NO, nitric oxide; ANOVA, analysis of variance. complications associated with non-insulin-dependent diabetes (NIDDM) differs from those associated with IDDM, raising the possibility that the functional evolution of microangiopathy is different [4]. In support of this hypothesis Shore et al. [5] found no evidence of an increase in capillary pressure in normotensive patients with NIDDM under resting conditions; neither was capillary filtration coefficient increased [6]. The ability to maximally dilate the vasculature has however been shown to be reduced in both NIDDM [7] and in subjects with impaired glucose tolerance [8].

Although it is not known whether this profoundly impaired vasodilatation reflects structural and/or functional changes it has been suggested that endothelial dysfunction may play an important role in the pathogenesis of diabetic microangiopathy in experi- 
Table 1. Characteristics of the subjects studied

\begin{tabular}{|c|c|c|}
\hline & NIDDM patients & Healthy control subjects \\
\hline$n$ (Males) & 14 & 14 \\
\hline Age (years) & $59.0 \pm 2.3$ & $58.9 \pm 2.6$ \\
\hline Duration of diabetes (years) & $9.1 \pm 1.9$ & \\
\hline Mean blood pressure $(\mathrm{mm} \mathrm{Hg}$ ) & $89 \pm 3$ & $95 \pm 2$ \\
\hline Body mass index $\left(\mathrm{kg} / \mathrm{m}^{2}\right)$ & $25.9 \pm 0.7$ & $26.2 \pm 1.0$ \\
\hline $\mathrm{HbA}_{1 \mathrm{c}}(\%)$ & $6.5 \pm 0.2$ & $4.8 \pm 0.1^{\mathrm{a}}$ \\
\hline Skin temperature $\left({ }^{\circ} \mathrm{C}\right)$ & $32.8 \pm 0.4$ & $33.3 \pm 0.3$ \\
\hline Warm sensory threshold $\left({ }^{\circ} \mathrm{C}\right)$ & $2.2 \pm 0.7$ & $1.2 \pm 0.4$ \\
\hline Cold sensory threshold $\left({ }^{\circ} \mathrm{C}\right)$ & $0.7 \pm 0.2$ & $0.4 \pm 0.1$ \\
\hline Vibration sensory threshold (V) & $5.4 \pm 0.4$ & $4.4 \pm 0.4^{b}$ \\
\hline $\begin{array}{l}\text { Complications } \\
\text { Retinopathy }\end{array}$ & $\begin{array}{l}7 \text { subjects no evidence of retinopathy } \\
6 \text { subjects background retinopathy } \\
1 \text { subject proliferative retinopathy }\end{array}$ & \\
\hline Nephropathy & $\begin{array}{l}11 \text { subjects no evidence of nephropathy } \\
3 \text { subjects raised urinary } \\
\text { albumin : creatinine ratio }\end{array}$ & \\
\hline Neuropathy & $\begin{array}{l}12 \text { subjects no evidence of neuropathy } \\
1 \text { subject autonomic and peripheral neuropathy } \\
1 \text { subject peripheral neuropathy }\end{array}$ & \\
\hline
\end{tabular}

Data are mean \pm SEM

Significant difference between diabetic and control groups a $p<0.001, n=14 ;{ }^{b} p<0.04, n=14$

mental diabetes [9, 10,], IDDM [11-14] and NIDDM $[15,16]$. As well as its role in transport, haemostasis and cell growth, the endothelium is an influential mediator of vascular tone, capable of synthesising nitric oxide (NO), prostaglandins and vasoactive peptides [17]. It has been proposed that NO is important in the acute response to acetylcholine and the delayed response to inflammatory stimuli in forearm skin microcirculation [18]. The latter action of NO may be of clinical relevance to NIDDM during the formation and healing of foot ulcers, common in this patient group [19].

The aim of this study was therefore to investigate the responses of the skin microcirculation to the iontophoretic application of acetylcholine, an endothelium-dependent vasodilator, and sodium nitroprusside, an NO donor, in patients with NIDDM. Heterogeneity of skin blood flow [20] makes interpretation of responses of the skin microcirculation to physiological and pharmacological interventions difficult, if perfusion is only measured at one site on the skin. The recently developed technique of laser Doppler perfusion imaging, which allows the mapping of tissue perfusion over a large number of immediately adjacent sites on the skin [21], was therefore used in this study to assess the microvascular responses.

\section{Subjects and methods}

Subjects. A total of 14 male NIDDM patients (defined as such when diagnosed at 33 years old or older with no ketones at time of diagnosis, and initially established on treatment with oral hypoglycaemic drugs or by diet alone) and 14 healthy control subjects, pair-matched for age, gave their fully informed witnessed written consent to this study which was approved by the local Medical Research ethics committee. The diabetic patients were controlled by either diet alone $(n=6)$ or diet plus insulin $(n=8)$. Subject characteristics are summarised in Table 1 . None of the subjects were taking any additional vasoactive agents. Subjects were asked to refrain from smoking on the day of the study and not to consume caffeine-containing drinks for at least $2 \mathrm{~h}$ before the start of the measurements.

Experimental protocol. These studies were carried out in a temperature controlled room $\left(21.5-22.5^{\circ} \mathrm{C}\right)$ with the subjects lying in the supine position. During the 30 -min acclimatization period the flexor aspect of the right forearm (the left in one subject) was gently cleaned with an alcohol wipe and then swabbed with deionised water. A thermocouple (Comark Electronic, Littlehampton, Sussex, UK) was then fixed to the volar aspect of the wrist in order to measure skin temperature. Blood pressure was determined by the mean of five readings taken at 1-min intervals using the oscillometric method and a semi-automatic blood pressure recorder (Dinamap, Critikon, Tampa, Fla., USA). Vibration Sensory Threshold was determined on the first and fourth fingers of the left hand using a biothesiometer (Biomedical Instrument Co., Newbury, Ohio, USA). A computerised thermal testing system (Middlesex Hospital, London, UK) was used to assess warming and cooling thermal sensory thresholds on the palm of the left hand. Blood glucose concentrations were measured in the diabetic patients at the beginning and end of the study (BM test 144, Refloflux II Meter; Boehringer Mannheim, Mannheim, Germany). $\mathrm{HbA}_{1 \mathrm{c}}$ (normal range, 4.0-6.0\%) measured by HPLC and renal function (plasma creatinine concentrations, normal range $45-125 \mu \mathrm{mol} / 1$ ) were measured in all subjects from a venous blood sample collected at the end of the study. Following acclimatization the skin erythrocyte flux was measured using laser Doppler perfusion imaging after application of acetyl- 
choline and sodium nitroprusside on the right forearm (the left in one subject) and maximum blood flow was measured on the left forearm (see relevant sections below).

Measurement of skin erythrocyte flux responses to acetylcholine and sodium nitroprusside by laser doppler perfusion imaging. A laser Doppler perfusion imager (LDPI) (Lisca PIM 1.0; Lisca Development $\mathrm{AB}$, Linköping, Sweden) was used to map skin perfusion. (A 1-mW Helium-Neon laser beam (wavelength $633 \mathrm{~nm}$ ) sequentially scans an area of tissue. The laser beam penetrates the tissue and a fraction of the light is backscattered by mobile erythrocytes and undergoes a frequency shift according to the Doppler principle, generating a signal proportional to tissue perfusion). This procedure is repeated at each measurement site (up to 4096 sites) producing a colour-coded image of skin erythrocyte flux on a computer monitor. The area of drug delivery could be clearly identified on the image as a coloured circular area against a grey background (black tape on the electrode chamber, see below). Iontophoresis was used to apply the substance being tested across the skin of the forearm. This is a non-invasive method of drug application which allows the local transfer of charged substances across the skin using a small electric current [22]. The current strengths chosen for this study were not felt by the majority of subjects and in the remainder only a mild prickling sensation was perceived. A perspex direct electrode chamber $(30 \mathrm{~mm}$ total diameter $\times 3 \mathrm{~mm}$ height, inner (drug) chamber $10 \mathrm{~mm}$ diameter) was used to deliver the drugs (Moor Instruments, Axminster, Devon, UK). The outer ring of the chamber was covered with non-reflective black tape in order to minimise artefacts on the LDPI's recordings and also to identify the direct site of drug delivery on the image produced. The chamber was attached to the forearm by means of a double-sided adhesive disc and an indifferent electrode was attached to the volar aspect of the wrist of the subject to complete the circuit. The position of the chamber was chosen in order to avoid hair, freckles and broken skin. The chamber was filled with the solution under test and covered with a glass cover slide to prevent reflection artefacts from the solution in the chamber. The head of the LDPI was positioned approximately $13 \mathrm{~cm}$ above the centre of the chamber and a black cloth placed over the LDPI and the forearm in order to minimise optical interference with the LDPI's signal. This experimental setup allowed the non-invasive measurement of skin erythrocyte flux directly over the site of drug application.

A battery-powered iontophoresis controller (MIC 1, Moor Instruments) was used to provide a direct current for drug iontophoresis. Acetylcholine (1\%) was delivered using an anodal current; $7 \times(0.1$ milliamps $(\mathrm{mA})$ for $20 \mathrm{~s})$, followed by $1 \times(0.2 \mathrm{~mA}$ for $20 \mathrm{~s})$, with $60 \mathrm{~s}$ interval between each dose (total charge 18 millicoulombs $(\mathrm{mC})$ ). Pilot studies demonstrated that a 60 -s interval between each iontophoresis period was required to achieve the plateau of the response following each delivery of acetylcholine. The responses to acetylcholine vehicle (3\% mannitol in water for injection) and acetylcholine were measured at one and two sites on the forearm, respectively. Forearm skin erythrocyte flux was recorded immediately before the start of iontophoresis and after each period of drug application with the LDPI set to scan $32 \times 32$ measurement sites, covering an area approximately $4 \times 4 \mathrm{~cm}$. The intrasubject reproducibility of this protocol was measured in eight healthy volunteers. The coefficient of variation of the maximum response to acetylcholine (determined as the point of maximum vasodilatation to acetylcholine when there was negligible vehicle response) was $16.3 \pm 3.7 \%$, at two or three measurement sites. Day-to-day reproducibility was $21.7 \pm 6.4 \%$, determined in 4 subjects on two to four occasions.

The $0.01 \%$ sodium nitroprusside was delivered using a cathodal current; $2 \times(0.1 \mathrm{~mA}$ for $20 \mathrm{~s})$, followed by $1 \times(0.2$ $\mathrm{mA}$ for $20 \mathrm{~s}$ ) with 180 -s intervals between each dose (total charge $8 \mathrm{mC}$ ). Pilot studies showed that the response to sodium nitroprusside required longer to develop than that to acetylcholine. The responses to sodium nitroprusside vehicle (deionised water) and sodium nitroprusside were measured at one and one or two sites on the forearm, respectively. Forearm skin erythrocyte flux was recorded immediately before the start of iontophoresis and at 0,60 , and $120 \mathrm{~s}$ following each period of drug application. Due to technical reasons the responses to sodium nitroprusside were only measured in 25 of 28 subjects. The intrasubject reproducibility of this protocol was measured in eight healthy volunteers. The coefficient of variation at the fifth point of measurement was $10.9 \pm 5.2 \%$, at two measurement sites. Day to day reproducibility was $31.0 \pm 13.2 \%$, determined in three subjects on two to three occasions.

At the end of each study, biological zeroes (that is, the flux value without arterial in-flow) were measured at both an untreated and a vasodilated site on the forearm during arterial occlusion of the upper arm by an inflated cuff. Day-to-day reproducibility of biological zero was $7.2 \pm 3.1 \%$ determined in three subjects on two to five occasions.

Analysis of the colour-coded images of erythrocyte flux obtained with the LDPI was carried out using the Pim 2.3 software package Lisca Development ab, Linköping Sweden. The responses to the direct application of acetylcholine and sodium nitroprusside were calculated as the mean of the erythrocyte flux of $80 \pm 2$ points, over a $0.78-\mathrm{cm}^{2}$ area of the forearm.

Measurement of maximum blood flow. This method is described in detail elsewhere [23]. In brief, an area of skin on the flexor aspect of the left forearm was heated to $42^{\circ} \mathrm{C}$ with a small brass heater (Moor Instruments) attached to the skin surface by means of a double-sided adhesive disc. After $30 \mathrm{~min}$ the maximum microvascular hyperaemic response (termed maximum blood flow) was measured using laser Doppler fluximetry (Periflux Pf2, Perimed, Stockholm, Sweden) ( $30 \mathrm{~s}$ to each of eight heated sites) and calculated as the mean erythrocyte flux of the eight skin sites.

Drugs. Acetylcholine (Miochol) was obtained from IOLAB (Bracknell, Berks. UK); the vehicle for acetylcholine, $3 \%$ mannitol in water for injection, was prepared by the Royal Devon and Exeter Hospital Pharmacy (Exeter, Devon, UK); sodium nitroprusside (Nipride), from Roche (Welwyn Garden City, Herts UK), was dissolved in sterile deionised water (sodium nitroprusside vehicle) obtained from Baxter Healthcare Ltd. (Thetford, Norfolk, UK). All drugs were freshly prepared immediately prior to administration and sodium nitroprusside was kept in the dark.

\section{Statistical analysis}

To remove any influence of vehicle on the analysis of the drug responses the results are expressed as the response to acetylcholine and sodium nitroprusside minus their respective vehicle responses. Assessment of drug-minus-vehicle responses were made using two-way analysis of variance for repeated measures (ANOVA) using the first five scans only as the vehicle response overwhelmed the sodium nitroprusside response at later iontophoresis periods. The same conclusions were 
reached whether statistical analyses were performed on the absolute responses to acetylcholine or sodium nitroprusside (statistical analysis not shown) or on the absolute drug responses minus respective vehicle responses. Comparisons between subject groups for biological zeroes, maximum blood flow and subject characteristics were made by Wilcoxon rank sum test. Paired Student's $t$-tests were used to compare the change in flux from baseline following drug and vehicle administration. Spearman rank-correlation coefficients $\left(\mathbf{R}_{\mathrm{s}}\right)$ were calculated were appropriate. Results are expressed in the text as percentage increase from basal flux, absolute values in arbitrary units of volts ( $V$ ) and responses to acetylcholine and sodium nitroprusside after subtraction of their respective vehicle responses (V). Data are presented in the text as mean \pm SEM.

\section{Results}

Basal forearm skin perfusion. Basal forearm skin perfusion was not significantly different in the NIDDM patients compared with the control subjects.

Response to acetylcholine. The responses of forearm skin erythrocyte flux to the iontophoresis of acetylcholine and acetylcholine vehicle in both NIDDM patients and control subjects are shown in Figure 1. Acetylcholine vehicle elicited a small but significant increase in the erythrocyte flux, from the fourth iontophoresis period onwards. This increase was similar in both NIDDM and control (e.g. $6.7 \pm 2.0 \%$ and $9.9 \pm 4.0 \%$ increase following the fourth iontophoresis from basal flux respectively; $p<0.161, n=14$ ) but negligible in comparison to the corresponding acetylcholine response (e.g. 109.2 $\pm 11.9 \%$ and $162.1 \pm$ $14.2 \%$; increase from basal flux respectively). To remove any influence of changes in tissue perfusion due to vehicle, the following results are expressed as erythrocyte flux to acetylcholine minus the vehicle response (Fig.2). Forearm tissue perfusion significantly increased following the iontophoresis of acetylcholine $(p<0.001)$, but the vasodilatation to acetylcholine was lower in the NIDDM group than the control subjects $(p<0.01)$.

Response to sodium nitroprusside Figure 3 shows the responses of forearm skin erythrocyte flux to the iontophoresis of sodium nitroprusside and sodium nitroprusside vehicle in 12 matched pairs of NIDDM patients and control subjects. The vasodilatory response to sodium nitroprusside vehicle (delivered with a cathodal current) was much more marked than to acetylcholine vehicle (delivered with an anodal current). For example, in control subjects the increase in flux from baseline following the second iontophoresis period was $76.9 \pm 22.5 \%$ to sodium nitroprusside vehicle compared with $4.4 \pm 2.1 \%$ to acetylcholine vehicle. Hence the following results are expressed as erythrocyte flux to sodium nitroprusside minus the vehicle response (Fig. 4). Forearm tissue

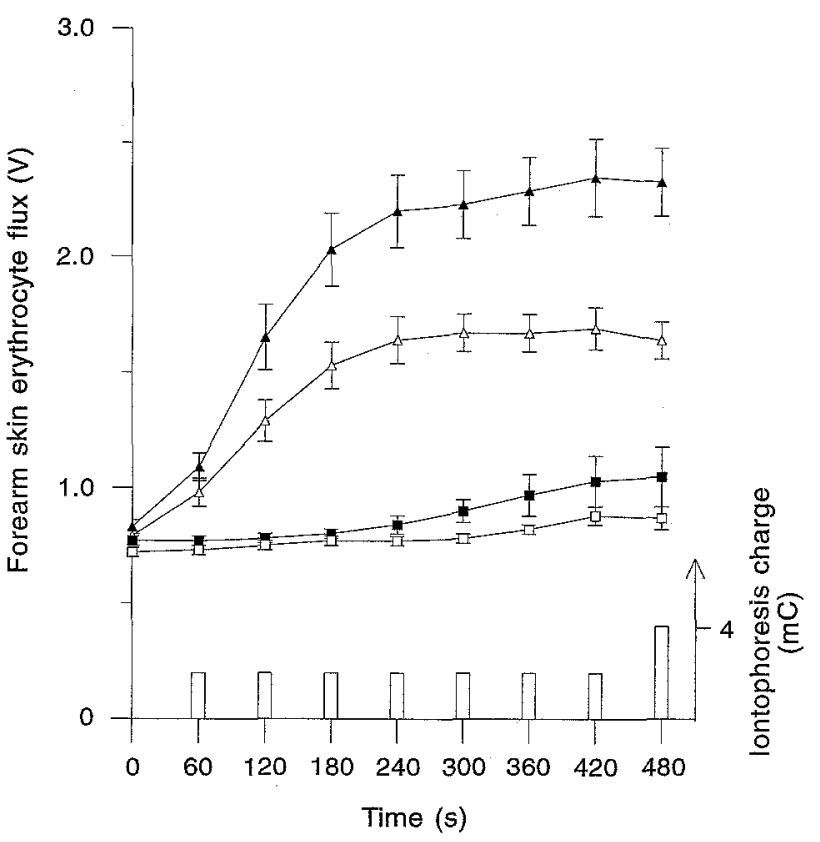

Fig. 1. Absolute forearm skin erythrocyte flux (Volts, mean $\pm \mathrm{SEM}, n=14$ ) following the iontophoresis of acetylcholine in NIDDM patients $(\triangle)$ and healthy control subjects $(\boldsymbol{A})$ and acetylcholine vehicle in NIDDM patients $(\square)$ and healthy control subjects $(\mathbf{\square})$

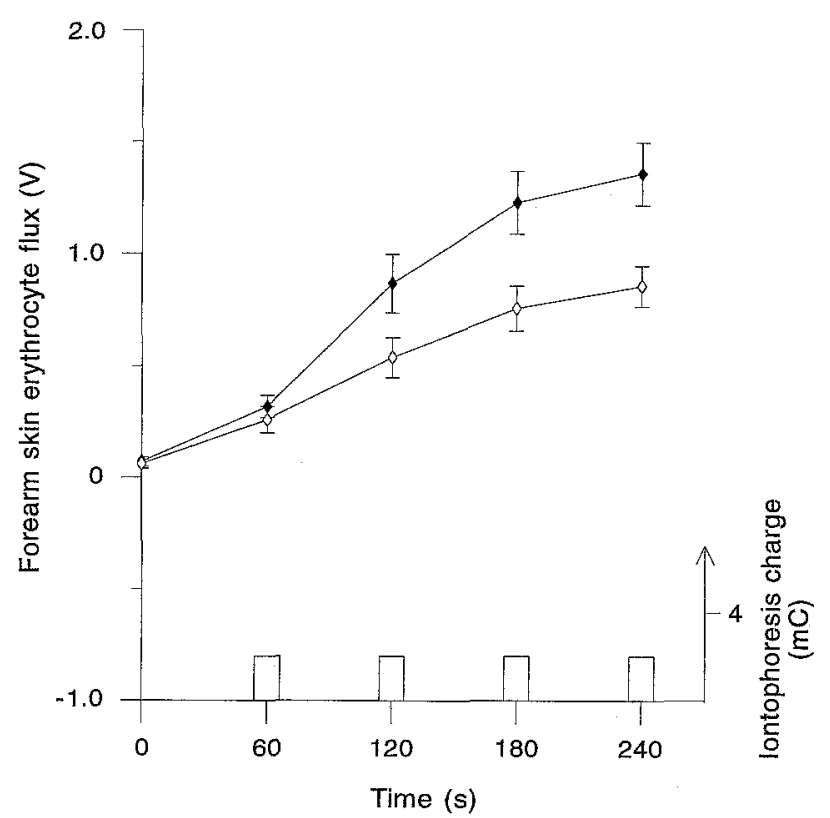

Fig. 2. Response of forearm skin erythrocyte flux (Volts, mean $\pm \mathrm{SEM}, n=14$ ) following the iontophoresis of acetylcholine minus the acetylcholine vehicle response in NIDDM patients $(\diamond)$ and healthy controls $(\diamond)$. The vasodilatation to acetylcholine was significantly lower in the NIDDM patients than the control subjects $(p<0.01)$

perfusion significantly increased following the iontophoresis of sodium nitroprusside $(p<0.001)$. The vasodilatation to sodium nitroprusside was lower in the NIDDM group than the control subjects $(p<0.01)$. 


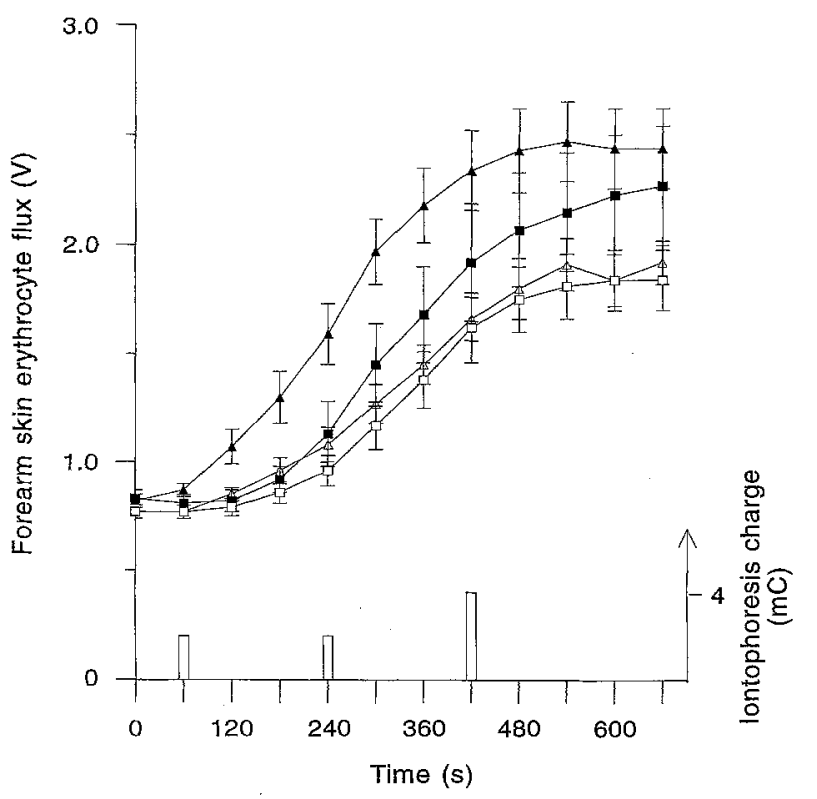

Fig.3. Absolute forearm skin erythrocyte flux (Volts, mean \pm SEM, $n=12$ ) following the iontophoresis of sodium nitroprusside in NIDDM patients $(\triangle)$ and healthy control subjects $(\boldsymbol{\Delta})$ and sodium nitroprusside vehicle in NIDDM patients ( $\square$ ) and healthy control subjects ( $\mathbf{a})$

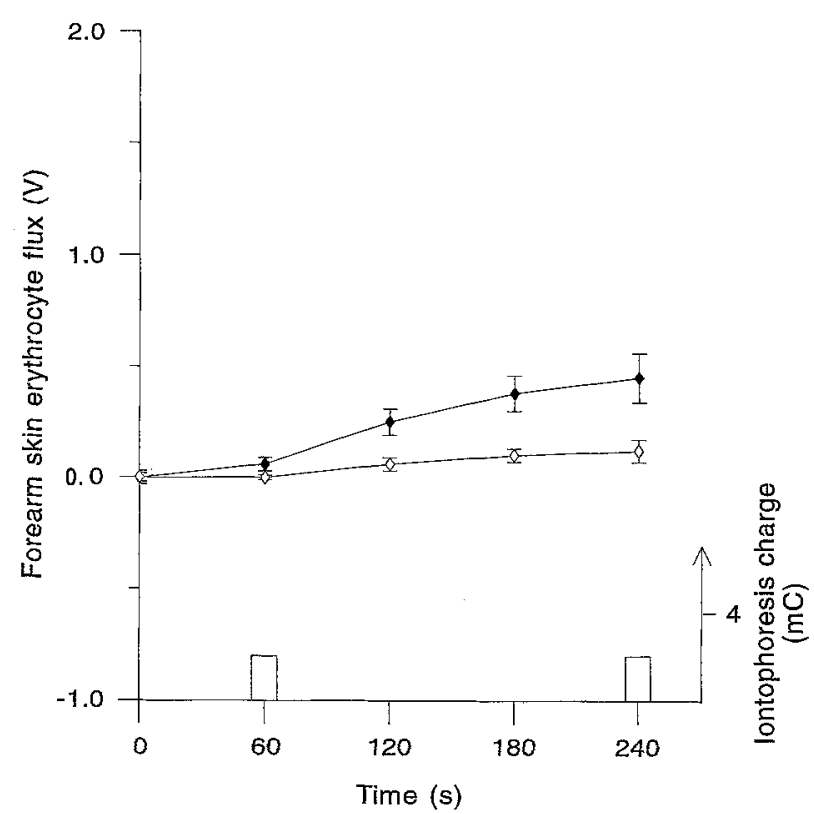

Fig.4. Response of forearm skin erythrocyte flux (Volts, mean $\pm \mathrm{SEM}, n=12$ ) following the iontophoresis of sodium nitroprusside minus the sodium nitroprusside vehicle response in NIDDM patients $(\diamond)$ and healthy control subjects $(\bullet)$. The vasodilatation to sodium nitroprusside was significantly lower in the NIDDM patients than the control subjects $(p<0.01)$

Biological zero. There was no significant difference between biological zero measured at an untreated site and a vasodilated site on the forearm, in both NIDDM subjects $(0.65 \pm 0.02$ vs $0.65 \pm 0.02 \mathrm{~V}$, respectively; $p<0.959, n=13$ ) and pair-matched control

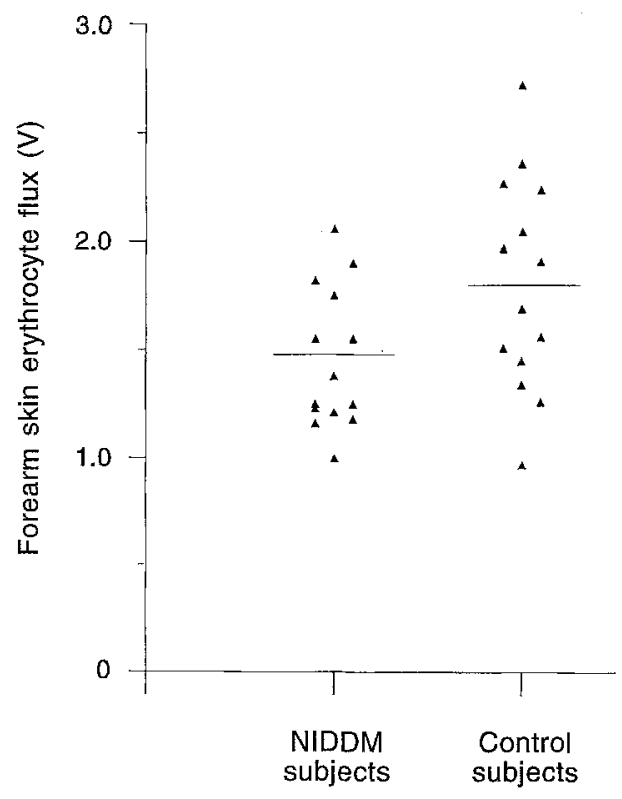

Fig.5. Forearm skin maximum blood flow in the forearm of NIDDM patients and healthy control subjects (Volts). Maximum blood flow was significantly lower in the NIDDM patients than the control subjects $(p<0.021, n=14)$

subjects $(0.68 \pm 0.02$ vs $0.72 \pm 0.03 \mathrm{~V}$, respectively; $p<0.311, n=12$ ). Mean biological zero was not significantly different between the NIDDM patients $(0.65 \pm 0.02 \mathrm{~V})$ and the control subjects $(0.69 \pm 0.02$ $\mathrm{V} ; p<0.300, n=14)$.

Maximum blood flow. The maximum microvascular hyperaemic response was attenuated in NIDDM patients compared to control subjects $(1.45 \pm 0.09$ vs $1.81 \pm 0.13 \mathrm{~V}, p<0.031, n=14$ ) (Fig. 5). In the NIDDM patient group maximum blood flow correlated with $\mathrm{HbA}_{1 \mathrm{c}}$ values $\left(\mathrm{R}_{\mathrm{s}}=-0.608, p<0.021\right)$, but not with the responses to acetylcholine and sodium nitroprusside or duration of diabetes.

There were no significant differences in either the responses to acetylcholine and sodium nitroprusside or the maximum skin blood flow response in patients with microvascular complications and those free of complications.

\section{Discussion}

This study suggests that the skin microvascular vasodilatory responses, assessed by laser Doppler perfusion imaging, to iontophoretically applied acetylcholine (which acts via the endothelium) and sodium nitroprusside (an NO donor, which acts directly on smooth muscle) are impaired in patients with NIDDM, treated with either diet alone or diet plus insulin, compared with age- and sex-matched control subjects.

The techniques of laser Doppler perfusion imaging and iontophoresis were combined, enabling the re- 
producible measurement of skin blood flow responses to vasoactive agents. Although iontophoresis provides a non-invasive technique to introduce charged substances across the surface of the skin, offering advantages over the use of intradermal injections, the study revealed the scope for misinterpretation with this technique. It was demonstrated, for example, that current alone may affect tissue perfusion. Vasodilatation to drug vehicle was observed with both anodal and cathodal currents, although the increase in erythrocyte flux to a cathodal current was observed after a lower total iontophoresis charge and was much more pronounced than that produced by an anodal current. The major pathway of iontophoretically applied substances across the skin is through areas of low electrical resistance such as sweat ducts, hair follicles and broken skin [22]. Sweat glands contain vasoactive substances such as kinins [24] which may possibly be iontophoresed along with the substance being tested, depending on their charge and size [25]. Transcutaneous electrical nerve stimulation has been utilised to stimulate axon reflex vasodilatation in the skin [26], although this method, in contrast to this study, uses painful stimuli it indicates that electrical charge alone may have a direct action on vascular tone. A combination of the above effects of iontophoresis could account for the observed response to current alone and the differences in the extent of vasodilatation to anodal and cathodal currents. These considerations make it essential for experiments using iontophoresis to control for both polarity of current and charge effects.

Our observations on the skin microcirculation are in agreement with those of McVeigh et al. [16] who demonstrated blunted endothelium-dependent and endothelium-independent forearm blood flow responses in patients with NIDDM, using venous occlusion plethysmography. These findings may implicate a role for abnormal endothelium and/or smooth muscle function in the pathogenesis of diabetic microangiopathy in NIDDM, and a number of contender mechanisms exist through which this impairment may be expressed.

Acetylcholine elicits vasodilatation through a complex sequence of events: when applied to blood vessels acetylcholine binds to muscarinic receptors on the surface of endothelial cells, which activates specific $G$ proteins, resulting in the production of NO from L-Arginine (catalysed by NO synthase). NO then diffuses across the intercellular gap, through the interstitial basement membrane and binds to the cytosolic guanylate cyclase of the smooth muscle cells. This induces a rise in cyclic guanosine monophosphate and consequently relaxation [17]. In addition to eliciting NO production acetylcholine also stimulates the release of the vasodilators prostacyclin and the putative endothelium-derived hyperpolarising factor [27] as well as vasoconstrictor prostanoids
[28] from the endothelium. Acetylcholine also inhibits the release of noradrenaline from nerves [29]. Therefore, the attenuated acetylcholine response of the skin microcirculation observed in NIDDM patients in this study may be attributed to abnormalities in one or several of these steps.

Although there is some evidence for abnormal muscarinic receptors or specific $G$ protein function in IDDM [14] there has been little investigation of these factors in NIDDM. However, some preliminary data suggests that there are differences in the responses to acetylcholine and bradykinin in isolated resistance arteries from NIDDM patients, indicating that abnormalities of muscarinic receptors or specific $\mathrm{G}$ protein function may exist [15]. Observations in experimental diabetes indicate that specific receptor abnormalities are not responsible for the abnormal acetylcholine response in diabetes as impaired vasodilatation has been demonstrated to other endothelium-dependent vasodilators such as histamine which do not act via muscarinic receptors [30]. Although care should be taken when applying information from animal models to man, these findings suggest that other mechanisms may be responsible for the impaired acetylcholine response observed in NIDDM.

A decrease in NO production could contribute to the attenuated vasodilatation following stimulation with acetylcholine, found in the NIDDM group. This mechanism was examined by McVeigh et al. [16], who were unable to demonstrate any difference in NO production, following acetylcholine stimulation, between NIDDM patients and healthy control subjects. They assessed NO production through the inhibition of NO synthesis with L-NMMA, a competitive inhibitor of NO synthase. However, their study did not demonstrate a vasoconstrictor effect of $\mathrm{L}-\mathrm{NMMA}$ on basal blood flow in either control subjects or diabetic patients which is in contention with previous findings [31] questioning the sensitivity of the experimental methods used. Therefore, an attenuated production of NO causing a reduced response to acetylcholine in NIDDM cannot be ruled out.

The vascular endothelium plays an important role in the control of vascular tone through the balanced release of both vasodilators, NO, prostacyclin and endothelium-derived hyperpolarising factor and vasoconstrictors, prostaglandins and endothelin. Evidence from experimental diabetes suggests that diabetes may be characterised by increased production or release of prostanoid constrictors which could act to attenuate the vasodilatory impaired endothelialdependent responses to acetylcholine $[32,28]$, although this is not a universal finding [33].

Another potential mechanism through which the response to acetylcholine may be diminished in NIDDM is via the impairment of NO diffusion from the endothelium to the underlying smooth muscle, 
and indeed a number of candidates have been proposed to effect this pathway in diabetes. The accumulation of advanced glycation end products, formed by the nonenzymatic glycation reaction between glucose and collagen, is heightened in diabetic basement membrane [34]. These products have been shown to impair endothelial-dependent relaxation in experimental diabetes through the quenching of NO [35]. $\mathrm{HbA}_{1 \mathrm{c}}$ levels of which are raised in diabetes, has also been reported to quench $\mathrm{NO}$ and therefore blunt NO-dependent responses [36]. Although this study did not find any correlation between $\mathrm{HbA}_{1 \mathrm{c}}$ levels and the response to acetylcholine or sodium nitroprusside in either the NIDDM group or control group this does not exclude an effect of advanced glycation end products as their accumulation will depend on long-term control and may not be adequately reflected in a single $\mathrm{HbA}_{1 \mathrm{c}}$ level. Increased free radical activity has been associated with diabetic microangiopathy [37], and may contribute to blunted endothelial-dependent responses in diabetes [38] as NO is degraded rapidly by these highly reactive species. Levels of oxidised low-density lipoproteins, raised in diabetes [39], may also cause defective endotheliumdependent responses in diabetes by inactivating $\mathrm{NO}$ [40].

The reduced response to acetylcholine in the NIDDM group observed in this study may not necessarily indicate endothelial dysfunction but could result from abnormalities of the smooth muscle function. This study has demonstrated a reduced response to the NO donor sodium nitroprusside in the skin microcirculation in NIDDM patients and implies that endothelium dysfunction may not solely be responsible for the blunted acetylcholine response observed. This finding in the skin microcirculation is in agreement with observations from the forearm skeletal muscle bed in NIDDM [16].

As discussed earlier one of the main routes of drugs applied by iontophoresis is through the sweat glands. Acetylcholine, as well as directly initiating endothelium-dependent vasodilatation, also binds to cholinergic receptors on the sweat glands in the skin leading to sweat production. As kinins [41], histamine [42] and prostaglandin-like activity [43] have all been reported to be present in sweat, it is possible that the tissue perfusion response observed to acetylcholine may be contributed to, at least in part, by these vasodilators. Even if this was the case these vasodilators all act via the endothelium and ultimately the measured response to acetylcholine would still be endothelium-dependent. As the group of patients investigated was relatively free of complications and the majority had no evidence of diabetic neuropathy, abnormalities of sweat production in response to iontophoresised acetylcholine are unlikely to explain the different perfusion responses observed in this study.
The observation that maximum blood flow in the forearm is reduced in NIDDM when compared to age- and sex-matched control subjects is consistent with previous data from the foot, although in this study the difference between the patients and control subjects is less marked [7]. Thickness of basement membrane increases with the distance away from the heart, an effect attributed to exposure to increased hydrostatic pressure [44]. Such a difference in basement membrane thickness may be a potential mechanism for the altered maximum blood flow responses between the forearm and feet. Maximum blood flow did not correlate with either the measured response to acetylcholine or sodium nitroprusside, which suggests that complex structural and functional mechanisms determine the microvascular maximum hyperaemic response.

In summary, laser Doppler perfusion imaging provides a non-invasive, reproducible method to assess the responses of the skin microcirculation to iontophoretically applied acetylcholine and sodium nitroprusside. The results of this study suggest that the function of the endothelium and/or smooth muscle may be abnormal in NIDDM. The mechanisms involved remain to be elucidated.

Acknowledgements. The authors wish to thank the Pharmacy Department at The Royal Devon and Exeter Hospital for preparation of the mannitol vehicle. S.J. Morris is a Wellcome Prize Student $(040230 / \mathrm{Z} / 93 / \mathrm{Z})$. This work was supported by The Wellcome Trust $(032627 / Z / 90 / Z / 1.27$ \& 039501/Z/93/Z).

\section{References}

1. Parving $H H$, Viberti GC, Keen $H$, Christiansen JS, Lassen NA (1983) Haemodynamic factors in the genesis of diabetic microangiopathy. Metabolism 32: 943-949

2. Sandeman DD, Shore AC, Tooke JE (1992) Relation of skin capillary pressure in patients with insulin-dependent diabetes mellitus to complications and metabolic control. N Engl J Med 327: 760-764

3. Jaap AJ, Shore AC, Tooke JE (1994) Capillary filtration coefficient is different in long duration type 1 diabetic patients with and without microvascular complications. Diabetic Med 2[Suppl 1]: S13 (Abstract)

4. Tooke JE (1989) Microcirculation and diabetes. Br Med Bull 45(1): 206-223

5. Shore AC, Jaap AJ, Tooke JE (1994) Capillary pressure in patients with NIDDM. Diabetes 43: 1198-1202

6. Jaap AJ, Shore AC, Gamble J, Gartside IB, Tooke JE (1994) Capillary filtration coefficient in type II (non-insulin-dependent) diabetes. J Diab Comp 8: 111-116

7. Sandeman DD, Pym CA, Green EM, Seamark C, Shore AC, Tooke JE (1991) Microvascular vasodilatation in feet of newly diagnosed non-insulin-dependent diabetic patients. BMJ 302: 1122-1123

8. Jaap AJ, Hammersley MS, Shore AC, Tooke JE (1994) Reduced microvascular hyperaemia in subjects at risk of developing type 2 (non-insulin-dependent) diabetes mellitus. Diabetologia 37: 214-216 
9. Kiff RJ, Gardiner SM, Compton AM, Bennett (1991) The effects of endothelin- 1 and $\mathrm{N}^{\mathrm{G}}$-nitro-L-arginine methyl ester on regional haemodynamics in conscious rats with streptozotocin-induced diabetes mellitus. Br J Pharmacol 103: 1321-1326

10. Taylor PD, Wickenden AD, Mirrlees DJ, Poston L (1994) Endothelial function in the isolated perfused mesentery and aortae of rats with streptozotocin-induced diabetes: effect of treatment with the aldose reductase inhibitor, ponalrestat. Br J Pharmacology 111: 42-48

11. de Tejada IS, Goldstein I, Azadzoi K, Krane RJ, Cohen RA (1989) Impaired neurogenic and endothelium-mediated relaxation of penile smooth muscle from diabetic men with impotence. New Engl J Med 320: 1025-1030

12. Calver A, Collier J, Vallance P (1992) Inhibition and stimulation of nitric oxide synthesis in the human forearm arterial bed of patients with insulin-dependent diabetes. J Clin Invest 90: 2548-2554

13. Elliott TG, Cockcroft JR, Groop PH, Viberti GC, Ritter JM (1993) Inhibition of nitric oxide synthesis in the forearm vasculature of insulin-dependent diabetic patients: blunted vasoconstriction in patients with microalbuminuria. Clin Sci 85: 687-693

14. McNally PG, Watt PA, Rimmer T, Burden AC, Hearnshaw JR, Thurston H (1994) Impaired contraction and endothelium-dependent relaxation in isolated resistance vessels from patients with insulin-dependent diabetes mellitus. Clin Sci 87: 31-36

15. Lawrence IG, Watt PAC, McNally PG, Burden AC, Thurston H (1994) Resistance artery structure and function in non-insulin-dependent diabetes mellitus (NIDDM). Diabetologia 37[Suppl 1]: A22 (Abstract)

16. McVeigh GE, Brennan GM, Johnston GD et al. (1992) Impaired endothelium-dependent and independent vasodilatation in patients with type 2 (non-insulin-dependent) diabetes mellitus. Diabetologia 35: 771-776

17. Vallance P, Collier J (1994) Biology and clinical relevance of nitric oxide. BMJ 309: 453-457

18. Warren JB (1994) Nitric oxide and human skin blood flow responses to acetylcholine and ultraviolet light. FASEB J 8: 247-251

19. Watkins PJ, Grenfell A, Edmonds M (1987) Diabetic complications of non-insulin-dependent diabetes. Diab Med 4: 293-296

20. Tenland T, Salerud EG, Nilsson GE (1983) Spatial and temporal variations in human skin blood flow. Int $\mathbf{J}$ Microcirc Clin $\operatorname{Exp} 2: 81-90$

21. Wårdell K, Jakobsson A, Nilsson GE (1993) Laser Doppler perfusion imaging by dynamic light scattering. IEEE Trans Biomed Eng 40 (4): 309-316

22. Harris R (1967) Iontophoresis. In: Licht E (ed) Physical medicine library, vol 4. Elizabeth Licht, Connecticut, pp 156-178

23. Rayman G, Williams SA, Spencer PD, Smaje LH, Wise PH, Tooke JE (1986) Impaired microvascular hyperaemic response to minor skin trauma in type I diabetes. BMJ 292: 1295-1298

24. Reynolds NI, Figueroa CD, Burton JL, Muller-Esterl W, Bhoola KD (1991) Tissue kallikrein and kininogen in human sweat glands and psoriatic skin. Br J Dermatol 124: 236-241

25. Ledger PW (1992) Skin biological issues in electrically enhanced transdermal delivery. Advanced Drug Delivery Reviews 9: 289-307
26. Westerman RA, Widdop RE, Hogan C, Zimmet P (1987) Non-invasive tests of neurovascular function: reduced responses in diabetes mellitus. Neurosci Lett 81: 177-182

27. Rubanyi GM (1991) Endothelium-derived relaxing and contracting factors. J Cell Biochem 46: 27-36

28. Tesfamariam B, Jakubowski JA, Cohen RA (1989) Contraction of diabetic rabbit aorta caused by endothelium-derived $\mathrm{PGH}_{2}-\mathrm{TxA}_{2}$. Am J Physiol 257 (Heart Circ Physiol 26): H1327-H1333

29. O'Rouke ST, Vanhoutte PM (1992) Vascular pharmacology. In: Loscalzo J, Creager MA, Dzau VJ (eds) Vascular medicine. A textbook of vascular biology and diseases. Little, Brown \& Co., Boston, pp 133-155

30. Tanz RD, Chang KS, Weller TS (1989) Histamine relaxation of aortic rings from diabetic rats. Agents Actions 28: 1-8

31. Vallance P, Collier J, Moncada S (1989) Effects of endothelium-derived nitric oxide on peripheral arteriolar tone in man. Lancet II: $997-1000$

32. Shimzu K, Muramatsu M, Kakegawa Yet al. (1993) Role of prostaglandin $\mathrm{H}_{2}$ as endothelium-derived contracting factor in diabetic state. Diabetes 42: 1246-1252

33. Taylor PD, McCarthy AL, Thomas CR, Poston L (1992) Endothelium-dependent relaxation and noradrenaline sensitivity in mesenteric resistance arteries of streptozotocininduced diabetic rats. Br J Pharmacol 107: 393-399

34. Brownlee M, Cerami A, Vlassara H (1988) Advanced products of nonenzymatic glycosylation and the pathogenesis of diabetic vascular disease. Diabetes Metab Rev 4: 437-451

35. Bucala R, Tracey KJ, Cerami A (1991) Advanced glycosylation products quench nitric oxide and mediate defective endothelium-dependent vasodilatation in experimental diabetes. J Clin Invest 87: 432-438

36. Rodriguez-Mañas L, Arribas S, Girón C, Villamor J, Sánchez-Ferrer CF, Marin J (1993) Interference of glycosylated human hemoglobin with endothelium-dependent responses. Circulation 88(1): 2111-2116

37. Jennings PE, Jones AF, Florkowski CM, Lunec J, Barnett $\mathrm{AH}$ (1987) Increased diene conjugates in diabetic subjects with microangiopathy. Diabet Med 4: 452-456

38. Tesfamariam B, Cohen RA (1992) Free radicals mediate endothelial cell dysfunction caused by elevated glucose. Am J Physiol 263 (Heart Circ Physiol 32): H321-H326

39. Bucala R, Makita Z, Koschinsky T, Cerami A, Vlassara H (1993) Lipid advanced glycosylation: pathway for lipid oxidation in vivo. Proc Natl Acad Sci USA 90: 6434-6438

40. Schmidt K, Graier WF, Kostner GM, Mayer B, Böhme E, Kukovetz WR (1991) Stimulation of soluble guanylate cyclase by endothelium-derived relaxing factor is antagonised by oxidised low-density lipoprotein. $\mathrm{J}$ Cardiovasc Pharmacol 17(3): S83-S88

41. Hibino T, Takemura T, Sato K (1994) Human eccrine sweat contains tissue kallikrein and kininase $\Pi$. J Invest Dermatol 102: $214-220$

42. Garden JW (1966) Plasma and sweat histamine concentrations after heat exposure and physical exercise. J Appl Physiol 21: 631-635

43. Frewin DB, Eakin KE, Downey JA, Bhattachejee P (1973) Prostaglandin-like activity in human eccrine sweat. Aust J Exp Biol Med Sci 51: 701-702

44. Vracko R, Benditt EP (1970) Capillary basal lamina thickening. Its relationship to endothelial cell death and replacement. J Cell Biol 47: 281-285 